PREPARED FOR THE U.S. DEPARTMENT OF ENERGY, UNDER CONTRACT DE-AC02-76CH03073

PPPL-3542

PPPL-3542

UC-70

Local Physics Basis of Confinement Degradation in JET ELMy H-Mode Plasmas and Implications for Tokamak Reactors

by

R.V. Budny, B. Alper, D. Borba, J.G. Cordey, D.R. Ernst, C. Gowers, C. Giraud, K. Gunther, T.S. Hahm, G. Hammett, N. Hawkes, L.D. Horton, G. Saibene, R. Sartori, E. Synakowski, M.G. von Hellermann, and K.-D. Zastrow

February 2001
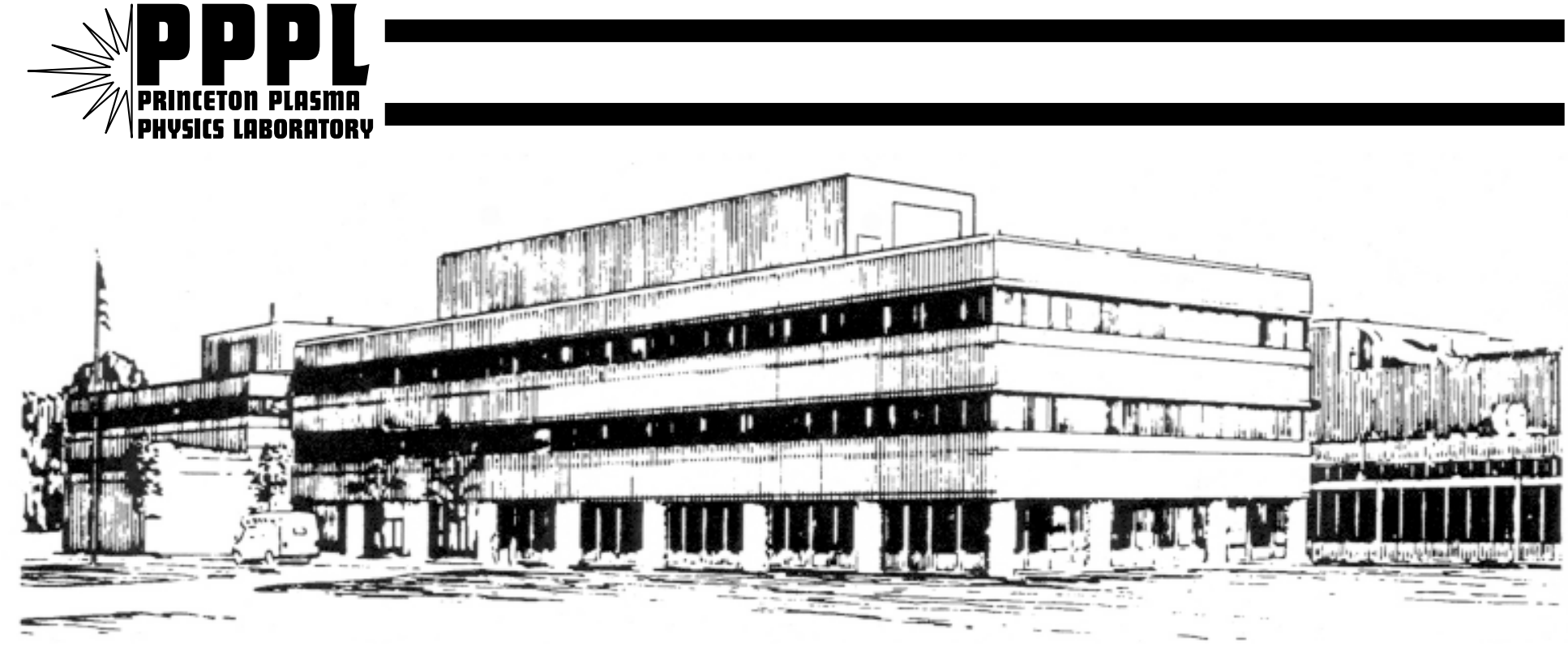

PRINCETON PLASMA PHYSICS LABORATORY PRINCETON UNIVERSITY, PRINCETON, NEW JERSEY 


\section{PPPL Reports Disclaimer}

This report was prepared as an account of work sponsored by an agency of the United States Government. Neither the United States Government nor any agency thereof, nor any of their employees, makes any warranty, express or implied, or assumes any legal liability or responsibility for the accuracy, completeness, or usefulness of any information, apparatus, product, or process disclosed, or represents that its use would not infringe privately owned rights. Reference herein to any specific commercial product, process, or service by trade name, trademark, manufacturer, or otherwise, does not necessarily constitute or imply its endorsement, recommendation, or favoring by the United States Government or any agency thereof. The views and opinions of authors expressed herein do not necessarily state or reflect those of the United States Government or any agency thereof.

\section{Availability}

This report is posted on the U.S. Department of Energy's Princeton Plasma Physics Laboratory Publications and Reports web site in Calendar Year 2001. The home page for PPPL Reports and Publications is: http://www.pppl.gov/pub_report/

DOE and DOE Contractors can obtain copies of this report from:

U.S. Department of Energy

Office of Scientific and Technical Information

DOE Technical Information Services (DTIS)

P.O. Box 62

Oak Ridge, TN 37831

Telephone: (865) 576-8401

Fax: (865) 576-5728

Email: reports@adonis.osti.gov

This report is available to the general public from:

National Technical Information Service

U.S. Department of Commerce

5285 Port Royal Road

Springfield, VA 22161

Telephone: 1-800-553-6847 or

(703) 605-6000

Fax: (703) 321-8547

Internet: http://www.ntis.gov/ordering.htm 


\title{
Local Physics Basis of Confinement Degradation in JET ELMy H-Mode Plasmas and Implications for Tokamak Reactors
}

\author{
R.V. Budny*, B. Alper ${ }^{\star}$, D. Borba ${ }^{\star}$, J.G. Cordey ${ }^{\star}$ D.R. Ernst*, C. Gowers ${ }^{\star}$, \\ C. Giraud ${ }^{\star}$, K. Gunther ${ }^{\star}$, T.S. Hahm* ${ }^{*}$ G. Hammett ${ }^{*}$, N. Hawkes ${ }^{\star}$, L.D. Horton ${ }^{\dagger}$, \\ G. Saibene ${ }^{\triangle}$, R. Sartori ${ }^{\triangle}$, E. Synakowski ${ }^{*}$, M.G. von Hellermann ${ }^{\ddagger}$, and K.-D. Zastrow ${ }^{\star}$ \\ JET JOINT UNDERTAKING, Abingdon, UK \\ *PPPL, Princeton University, P.O. Box 451, Princeton, NJ 08543, USA \\ *UKAEA Science Center, Culham, Oxfordshire, United Kingdom \\ •Assoc. EURATOM/IST, Av Rovisto Pais, 1096 Lisbon, Codex, Portugal \\ ${ }^{\dagger}$ MPI für Plasmaphysik, 2 Boltzmannstrasse, D-85748 Garching, Germany \\ $\triangle$ EFDA Close Support Unit, MPI für Plasmaphysik, 2 Boltzmannstrasse, D-85748 Garch- \\ ing, Germany \\ $\ddagger$ FOM Institute for Plasma Physics Rijnhuizen, 3430 BE Nieuwegein, NL \\ e-mail contact of main author: budny@princeton.edu
}

\begin{abstract}
First results of gyrokinetic analysis of JET ELMy H-mode plasmas are presented. ELMy $\mathrm{H}$-mode plasmas form the basis of conservative performance predictions for tokamak reactors of the size of ITER. Relatively high performance for long durations has been achieved and the scaling appears to be favorable. It will be necessary to sustain low $Z_{\text {eff }}$ and high density for high fusion yield. This paper studies the degradation in confinement and increase in the anomalous heat transport observed in two JET plasmas: one with an intense gas puff, and the other with a spontaneous transition between Type I to III ELMs at the heating power threshold. Linear gyrokinetic analysis gives the growth rate, $\gamma_{\text {lin }}$ of the fastest growing modes. The flow-shearing rate $\omega_{\mathrm{E} \times \mathrm{B}}$ and $\gamma_{\text {lin }}$ are large near the top of the pedestal. Their ratio decreases approximately when the confinement degrades and the transport increases. This suggests that tokamak reactors may require intense toroidal or poloidal torque input to maintain sufficiently high $\left|\omega_{\mathrm{E} \times \mathrm{B}}\right| / \gamma_{\text {lin }}$ near the top of the pedestal for high confinement.
\end{abstract}

\section{Introduction}

The H-mode regime in the Edge Localized Mode (ELM) phase is favored for large, conventional tokamak reactors since it has obtained enhanced performance for long durations. Deuterium-tritium experiments in JET ELMy plasmas have achieved $Q_{d t}=0.2$ [1]; however the confinement in similar plasmas tends to degrade as the density is pushed towards the Greenwald limit by gas puffing [2] or pellet injection [3]. This degradation is often associated with the transition from Type I to III ELMs [4]. Experiments in some other tokamaks and recently in JET have produced ELMy H-mode plasmas with high confinement near the Greenwald limit, but not with DT plasmas.

Toroidal nonlinear theory indicates that the microturbulence which is believed to cause anomalous transport is reduced by shear in the $E \times B$ rotation (more specifically, the $E \times B / R B_{P o l}$ rotation induced by $E_{r}$ ), quantified by the shearing rate $\omega_{\mathrm{E} \times \mathrm{B}}$, defined below [5]. A measure of this reduction can be given by the ratio of $\left|\omega_{\mathrm{E} \times \mathrm{B}}\right|$ and the linear growth rate $\gamma_{\text {lin }}$ of the most unstable toroidal mode with high toroidal mode number. Simulations indicate that where this ratio is less than $\simeq 1$, the plasma is expected to have reduced confinement [6]. This effect can be summarized in:

$$
\chi_{\mathrm{i}}=\chi_{0} \max \left(0,\left[1-\alpha_{\mathrm{exb}} \frac{\omega_{\mathrm{E} \times \mathrm{B}}}{\gamma_{\text {lin }}}\right]\right)
$$


where $\chi_{0}$ gives the transport in the hypothetical plasma with the same conditions, except with zero $\omega_{\mathrm{E} \times \mathrm{B}}$, and $\alpha_{\mathrm{exb}}$ is a constant of order 1 .

There is experimental evidence that $\omega_{\mathrm{E} \times \mathrm{B}}$ can have an influence on the confinement. Some plasma regimes, such as those with weak or reversed magnetic shear in JET and other tokamaks, have achieved considerably lower transport transiently, with ion thermal and particle transport near the neoclassical level. Generally these regimes have relatively large $\omega_{\mathrm{E} \times \mathrm{B}}$, with magnitude significantly larger than the computed maximum growth rate, $\gamma_{\text {lin }}$, of high n-toroidal modes associated with microturbulence. An example of $\omega_{\mathrm{E} \times \mathrm{B}}$ and $\gamma_{\text {lin }}$ analysis for a JET "optimized magnetic shear" plasma is given in Ref. [7].

Experiments where $\omega_{\mathrm{E} \times \mathrm{B}}$ is varied by changing the applied torque also suggest that $E \times B$ shear plays a fundamental role in governing the confinement in these regimes [8] [9]. There is also experimental evidence that modifying the rotation-dominated $E \times B$ shear can influence the local transport in a continuous fashion, even when transport rates far exceed the neoclassical values [10], [11], [12].

JET ELMy H-mode plasmas heated by neutral beam injection (NBI) have large toroidal rotation rates $f_{\text {tor }}$, with Mach numbers near unity in the center. Empirical fits to the dimensionless heat transport $\left(\chi_{\mathrm{i}} /\left(\Omega_{\mathrm{i}} L_{T i}^{2}\right)\right)$, normalized by the local ion gyrofrequency $\Omega_{\mathrm{i}}$ and $T_{i}$ scale length $\left(L_{T i} \equiv-T_{i} /\left(\partial T_{i} / \partial r\right)\right)$, indicate a reduction with increasing Mach number, [13], further suggesting that $\omega_{\mathrm{E} \times \mathrm{B}}$ plays a role.

This paper studies the energy transport and $\gamma_{\text {lin }}$ in JET ELMy H-mode plasmas with NBI heating and degradation in confinement. Evidence is presented that, at least in these NBI-heated plasmas, $\omega_{\mathrm{E} \times \mathrm{B}}$ plays a role in the degradation of confinement and increase in local heat transport. Energy confinement degradation occurs, in this picture, as a consequence of changes in the beam-induced rotation at high density causing the reduction of $\left|\omega_{\mathrm{E} \times \mathrm{B}}\right| / \gamma_{\text {lin }}$.

The results suggest that if tokamak power-producing reactors require high confinement in the ELMy H-mode regime, a large $\left|\omega_{\mathrm{E} \times \mathrm{B}}\right| / \gamma_{\text {lin }}$ will be required. An external source of $\omega_{\mathrm{E} \times \mathrm{B}}$ near the top of the pedestal may be sufficient to obtain high confinement.

A brief summary was presented at the 2000 IAEA conference [14]. A recent reanalysis of the charge-exchange geometry has resulted in corrections to data for the lower power plasma. This does not change our conclusions.

\section{Data}

Parameters for the two JET plasmas are summarized in the Table I. Both plasmas experience a decrease in confinement, as seen in the $W_{d i a}, H_{89}$, and $H_{97}$ traces in Fig. 1 . One plasma is dominantly tritium, with intense gas puffing to achieve high density, making it the more reactor relevant of the two. The line-averaged electron density $\bar{n}_{e}$ increased to 87 per cent of the Greenwald limit $\left(I_{p} / \pi \mathrm{a}^{2}\left[\mathrm{MAm}^{2}\right]\right)$ as a result of $T_{2}$ gas injection into the scrape off at a rate of $1.3 \times 10^{22}$ atoms / sec. The Troyon-normalized pressure, $\beta_{\mathrm{N}}$ reached 1.53 just as the intense puff started, then decreased gradually. The H-mode started with a brief phase of "transition Type III" ELMs at $17.1 \mathrm{~s}$, followed by an ELM-free phase, 
during which the puffing started, evolving to Type I ELMs at $18.5 \mathrm{~s}$, and then gradually, around 19.2-19.9 s, to "density-limit' Type III" ELMs. More details of this plasma and comparisons with similar plasmas are given in [2].

The other plasma is dominantly deuterium, with sufficiently low NBI power to be at the threshold for the transition between Type I to III ELMs. The plasma has an ELM-free H-mode phase from 18.3 to 20.8 s, followed by a Type I phase until $21.6 \mathrm{~s}$, followed by a Type III phase ending at 25.6s. A marked loss of confinement is seen in the line-integrated electron density and stored energy traces during the Type III phase. The confinement recovers during an ELM-free phase near the end of the NBI. Although this plasma is less reactor relevant than the first, this plasma strengthens the theoretical understanding of confinement degradation.

One of our main results is that the suppression ratio $\left|\omega_{\mathrm{E} \times \mathrm{B}}\right| / \gamma_{\text {lin }}$, near the top of the pedestal tends to decrease to low values (reduction of suppression) when $W_{d i a}$ and the confinement decrease. The time evolution of this ratio at several radii near the top of the pedestal are shown in the bottom of Fig. 1. The times chosen for the gyrokinetic analysis are indicated by the vertical dashed lines in the Figure. Some radii show a moderate decrease in the suppression ratio comparable to the magnitude of the decrease in $W_{d i a}$ with increasing density.

The thermal energy densities, shown in Fig. 2, shift up or down with the global $W_{\text {dia }}$, shown in Fig. 1, i.e., the profiles are "stiff" suggesting that the energy diffusivity does not appear to depend sensitively on a temperature. The vertical dashed lines indicate the approximate location of the top of the pedestal, as indicated by the Light Detection and Ranging (LIDAR) measurements of $n_{e}$ and $T_{e}[15]$.

The $n_{e}$ profiles used for the modeling were extrapolated form the LIDAR measurements using chordal densities measured by interferometry. The profiles change significantly in time with the energy confinement of the two plasmas: increasing in 43002, and decreasing in 49687.

Profiles for $T_{i}, Z_{\text {eff }}$, and the toroidal rotation rate, $f_{\text {tor }}$ were measured during the NBI phase using charge-exchange spectroscopy [16]. The profiles of $Z_{\text {eff }}$ are derived from measurements of the impurity densities. For 43002, the $\mathrm{He}, \mathrm{Be}$, and $\mathrm{C}$ impurity densities were measured. For 49687, the $\mathrm{C}$ impurity density was measured. The x-variable used in the Figures is $x \equiv \sqrt{\text { normalized toroidal flux }}$ which is roughly equal to the normalized minor radius of the flux surface, $r / a$. The mapping of the measured data to $x$ was done by the TRANSP code, discussed in the next Section. The measurements extend to a major radius near $\mathrm{R}=3.75 \mathrm{~m}$, i.e., $x \simeq 0.88$.

We extended the $T_{i}$ data out towards the edge using measurements from an edge spectroscopy system [17]. Examples are shown in Fig. 3. Near the mid-radius, the profiles tend to be stiff. This is indicated several ways: The profiles of the major-radius-normalized gradient scale length is relatively constant in time, as shown in Fig. 4. The ion heat conduction coefficient $\chi_{\mathrm{i}}$ tends to increase rapidly as $\frac{R}{L_{T i}}$ increases past a critical value (in the vicinity of $\frac{R}{L_{T i}} \simeq 5$. As shown below, $\frac{R}{L_{T i}}$ appears to be governed by a critical 
gradient, $\frac{R}{L_{T}^{\text {crit }}}$ over much of the profile. The measured toroidal rotation $f_{\text {tor }}$ behaves very similarly to $T_{i}$, as shown in Fig. 5 .

Below we analyze the heat transport in the plasmas, and correlate the increase in transport and degradation of confinement with decreases in $\left|\omega_{\mathrm{E} \times \mathrm{B}}\right| / \gamma_{\text {lin }}$. MHD also can increase transport and degrade confinement. For 43002, the mode with largest measured amplitude, having $\mathrm{n}=2$ is first observed in the magnetic probes after $18.5 \mathrm{sec}$, when the plasma transitions from ELM-free to Type I ELMs. This mode has a maximum amplitude of $\delta B=(2-3) \times 10^{-4} T$ at the probe location and lasts until 22.0 sec. The amplitude decreases during the $3.5 \mathrm{sec}$ period in which the mode is observed, and by 21.5 sec the amplitude is $\delta B<6 \times 10^{-5} \mathrm{~T}$. The frequency of the perturbation decreases from 14 to $7 \mathrm{kHz}$ due to the decrease in the plasma toroidal rotation frequency. This type of instability can degrade the plasma energy confinement, but in this plasma, the amplitude is small and decreasing when the confinement degradation is increasing, and thus it does not appear to be the main cause of the degradation. The fit to the data from the 9 Mirnov coil array gives $(\mathrm{m}, \mathrm{n})=(3,2)$ for this mode. Fourier Analysis of the fast electron-cyclotron emission (ece) channels gives the outer major radius location of the mode at $20.5 \mathrm{sec}$ at 3.30-3.42 $\mathrm{m}$. This is close to the region where TRANSP calculates $\mathrm{q}=1.5$, and is deeper inside the plasma than the region where the calculated microinstability linear growth is positive.

\section{TRANSP analysis}

The TRANSP plasma analysis code [18] is used to analyze the heat transport and $\omega_{\mathrm{E} \times \mathrm{B}}$. TRANSP is an interpolative code, making maximal use of measurements and minimal assumptions. In order to get relatively smooth, quasi steady-state profiles for $\chi_{\mathrm{i}}$ and $\omega_{\mathrm{E} \times \mathrm{B}}$, and to average over channel-to-channel systematic variations, we smoothed the profiles in time with an averaging window of up to 200 msec. Sawteeth mixing change profiles near the center, and ELMs change profiles near the pedestal. The time-averaging of the data removes information about the sawteeth and ELMs. This paper focuses on quasi steady-state phenomena, with gyrokinetic analysis at relatively few points in time, so the sawteeth and ELM time dependence is ignored.

TRANSP simulates the measured stored energy accurately, as shown in Fig. 6. This increases the credibility of the TRANSP calculations of the fast-ion energy density, power and torque deposition, and heat transport.

The NBI torque deposition is shown in Fig. 7. For 43002, as the density increases, both the NBI heating and torque decrease in the center as the penetration decreases with increasing density. Most of the NBI sources for this plasma had a full energy component of $150 \mathrm{keV}$. These decreases of heating and torque in the center correlates with the reduction of the central $T_{i}$ and $f_{\text {tor }}$ shown in Figs. $3-5$. The flattening of the $f_{\text {tor }}$ profile causes the reduction of $\omega_{\mathrm{E} \times \mathrm{B}}$, discussed below. For 49687 , with a decrease in density, the NBI torque and heat deposition show little change in shape.

The heat transfer, $\chi_{\mathrm{i}}$ for 43002 (Fig. 8-a), decreases during the ELM-free phase until the start of the $T_{2}$ puff. During the puff, the values have relatively little change in the core region $(R<3.6 m)$; however, outside $R=3.6 \mathrm{~m}$ the values increase, especially near 
the pedestal, and after the transition to Type III ELMs. For 49687, a large increase in $\chi_{\mathrm{i}}$ is seen across most of the profile when the energy confinement degrades. When the confinement recovers around $26 \mathrm{~s}, \chi_{\mathrm{i}}$ reduces. The effective ion and electron heat $\chi_{\mathrm{eff}}$ shows similar trends. The correspondence between the variable $x$ and the major radius $\mathrm{R}$ is shown in the Fig.

\section{Flow shear and growth rates}

The radial electric field profile, $E_{r}$ is calculated from the force balance of the trace carbon impurity:

$$
\begin{gathered}
\nabla(p)=e Z(E+v \times B) \\
E_{r}=v_{\text {Tor }} B_{\text {Pol }}-v_{\text {Pol }} B_{\text {Tor }}+\frac{1}{Z_{\text {imp }} e n_{\text {imp }}} \nabla\left(p_{\text {imp }}\right)
\end{gathered}
$$

where $n_{\text {imp }}$ and $p_{\text {imp }}$ are the measured impurity density and pressure $\left(\propto n_{\mathrm{imp}} T_{\mathrm{imp}}\right)$, and $Z_{\text {imp }}$ is the charge of the impurity (6 here). $B_{P o l}$ is calculated by TRANSP solving the poloidal field diffusion. Since the poloidal rotation profile is not measured, we use a neoclassical expression to compute $v_{P o l}[19]$, [20]. In general, for JET ELMy H-mode plasmas, the impurity pressure is a very small contribution to $E_{r}$, except possibly in the pedestal and edge. Not enough plasma measurements are available in the pedestal for us to study details in that region, so we focus on the region between the core and the top of the pedestal. Since the NBI in JET is unidirectional (co), NBI-heated ELMy plasmas have $\omega_{\mathrm{E} \times \mathrm{B}}$ and $E_{r}$ dominated by the toroidal rotation term. The profiles show little change in shape during the times of interest here.

The shearing rate on the outer midplane is given in terms of $E_{r}$ (Ref. [5]) by:

$$
\omega_{\mathrm{E} \times \mathrm{B}}=\left(\frac{R^{2} B_{P o l}^{2}}{B}\right) \frac{\partial}{\partial \psi}\left(\frac{E_{r}}{R B_{P o l}}\right) \simeq\left(\frac{R B_{P o l}}{B}\right) \frac{\partial}{\partial R}\left(\frac{E_{r}}{R B_{P o l}}\right)
$$

The results for $E_{r}$ shows little change in shape, with magnitude evolving in time similar to $f_{\text {tor }} .\left|\omega_{\mathrm{E} \times \mathrm{B}}\right|$ peaks near the pedestal, as shown in Fig. 9. For 43002, the peak decreases about a factor of two as the confinement degrades, while for 49687, the peak decreases by a smaller fraction.

\section{Gyrokinetic analysis}

Low frequency, electrostatic drift-type instabilities, driven by ion temperature gradient (ITG) and/or trapped-particle dynamics, are candidates for the anomalous transport generally observed in tokamak plasmas. We used the comprehensive electromagnetic GS2 code [21] to calculate the linear growth rate $\gamma_{\text {lin }}$ and the real part of the mode frequency $\omega_{\text {lin }}$ for the fastest growing mode. GS2 is an initial-value code which solves the linearized gyrokinetic equation in a general flux tube geometry. A new TRANSP postprocessor generates the GS2 inputs [22]. We used up to seven species: thermal electrons, thermal hydrogenic ions, one impurity, and the fast ions from the NBI.

GS2 assumes a fixed product of the poloidal mode number $k_{\theta}(=\mathrm{nq} / \mathrm{r}$ in the circular approximation) and the ion gyro-radius $\rho_{i}$. We scanned $k_{\theta} \rho_{i}$ at each time-zone to maximize 
$\gamma_{\text {lin }}$. Plots of the spectra at two time-zones during the reduced confinement phases of the plasmas are shown in Figs. 10-11. At low values of $k_{\theta} \rho_{i}(<1), \gamma_{\text {lin }}$ has a broad peak versus $k_{\theta} \rho_{i}$ with a maximum value around $k_{\theta} \rho_{i}=0.30-0.50$. This value is around the values typically found in gyrokinetic and gyrofluid simulations [23]. The mode frequency $\omega_{\operatorname{lin}}$ is positive (in the diamagnetic direction), typical of the ITG branch. At larger values of $k_{\theta} \rho_{i}, \omega_{\text {lin }}$ changes sign and the trapped electron mode (TEM) branch dominates. The ITG and TEM branches can interact non-linearly, but we have not studied that interaction.

The "mixing length" estimate of $\chi_{\mathrm{i}}$, is also shown in Figs. 10-11. This is defined by

$$
\chi_{\operatorname{mix}}=\gamma_{\text {lin }} /\left(k_{\theta}^{2}+<k_{r}^{2}>\right)
$$

where $\left\langle k_{r}^{2}\right\rangle$ is the flux-tube average of the radial $k_{r}$. $\chi_{\text {mix }}$ peaks at low values of $k_{\theta} \rho_{i}$ for both plasmas, suggesting that low $k_{\theta} \rho_{i}$ modes cause most of the anomalous transport. For this reason, we used the lower values of $\gamma_{\text {lin }}$ from the ITG branch in this paper.

We compare the measured $T_{i}$ gradient with the IFS-PPPL model [24] estimate of the critical value in Fig. 12. Near the mid-radius of both plasmas, the major-radius normalized gradient, $R / L_{T i}$, is close to the critical value, $R / L_{c r i t}$. The IFS-PPPL model was calibrated in the core, not the edge or pedestal, and was calibrated for the ITG branch, not the TEM branch.

Generally $\gamma_{\text {lin }}$ is positive over a significant portion of the major radius near the outer midplane. Both $\left|\omega_{\mathrm{E} \times \mathrm{B}}\right|$ and $\gamma_{\text {lin }}$ peak near the pedestal, as shown in Figs. 13 . At the region of peak $\gamma_{\text {lin }},\left|\omega_{\mathrm{E} \times \mathrm{B}}\right| / \gamma_{\text {lin }}$ is of order 0.5-2.0, as shown in Fig. 1. Deeper in the plasma (near the mid-radius) a state of marginal stability is maintained in the sense that $\gamma_{\text {lin }}$ and $\chi_{\mathrm{i}}$ depends sensitively on $R / L_{T i}$, which is close to its critical value. This is consistent with the observation that $\chi_{\mathrm{i}}$ remains larger than approximately five times the neoclassical level over a wide range of densities and operating conditions. For 49687 with a wider variation in confinement, $\left|\omega_{\mathrm{E} \times \mathrm{B}}\right| / \gamma_{\text {lin }}$ decreases to relatively low values, and then recovers when the confinement recovers.

Profiles of $\gamma_{\text {lin }}$ at various times are shown in Fig. 14. For $43002, \gamma_{\text {lin }}$ is relatively constant in time, decreasing slightly. The reduction in $\omega_{\mathrm{E} \times \mathrm{B}}$ causes the ratio $\left|\omega_{\mathrm{E} \times \mathrm{B}}\right| / \gamma_{\text {lin }}$ to decreased roughly 20 percent near the top of the pedestal, as the global confinement decreases roughly 20 percent. For $49687, \gamma_{\text {lin }}$ increases considerably while $\omega_{\mathrm{E} \times \mathrm{B}}$ remains relatively constant, thus $\left|\omega_{\mathrm{E} \times \mathrm{B}}\right| / \gamma_{\text {lin }}$ is reduced.

\section{Summary and Discussion}

We presented transport and micro-instability results for two JET ELMy H-mode plasmas with degradation of confinement associated with the transition from the Type I to III ELMy phase. The ion and effective heat conduction transport coefficients increase as the global and local energy confinement degrades. We calculated $E_{r}$ using the measured carbon temperature and toroidal rotation rate, and estimating the poloidal rotation using neoclassical theory. The magnitude of $\omega_{\mathrm{E} \times \mathrm{B}}$ calculated from $E_{r}$ has a peak near the top of the pedestal which decreases with confinement.

The gyrokinetic simulations show that the plasmas are near marginal stability except for 
ITG / trapped ion modes. For 43002, the growth rate $\gamma_{\text {lin }}$ of the fastest growing mode is relatively constant while $\omega_{\mathrm{E} \times \mathrm{B}}$ decreases, but $\left|\omega_{\mathrm{E} \times \mathrm{B}}\right|$ remains larger or comparable to $\gamma_{\text {lin }}$. The degradation of energy confinement and increase in local heat transport with increasing density are correlated with a slight decrease in the ratio $\left|\omega_{E \times B}\right| / \gamma_{\text {lin }}$. For 49687, $\omega_{\mathrm{E} \times \mathrm{B}}$ remains relatively constant while $\gamma_{\text {lin }}$ increases significantly, causing a large decrease in $\left|\omega_{E \times B}\right| / \gamma_{\text {lin }}$, consistent with the significant loss of confinement. Thus the criterion for reduction of the microturbulence, $\alpha_{\mathrm{exb}}\left|\omega_{\mathrm{E} \times \mathrm{B}}\right| \simeq \gamma_{\mathrm{lin}}$, with $\alpha_{\mathrm{exb}} \simeq 0.5-2.0$ (Eq. 1) appears to be applicable to this plasma within $10-15 \mathrm{~cm}$ of the top of the pedestal.

Other effects could contribute to the decrease in local energy confinement and increase in transport. For instance, the collisionality in the edge increases for 43002 and decreases for 49687. This contrasts with the observation that in JET H-mode plasmas, the edge collisionality generally increases at the transition from Type I to III ELMs [4]. Recent non-linear gyrokinetic simulations indicate that increasing collisionality damps the zonal flows that also contribute to reduce turbulence [25], so increased collisionality is predicted to lead to increased transport. As yet, we have not calculated this effect.

The ELMs effect the pedestal, and their effects extend further inward. The gyrokinetic analysis indicates unstable modes peaking around $3.7 \mathrm{~m}$, about $10 \mathrm{~cm}$ inside the pedestal, but also extending inward to $3.3 \mathrm{~m}$. It is unlikely that the ELMs could have a direct (local) effect this deep in the plasma. However, changes in the pedestal will effect the gradients, causing changes in confinement. Although the GS2 analysis is non-local in the poloidal direction, it is local in the radial direction, depending only on local plasma parameters such as $T_{i}$, and gradients. Thus the indirect effects in the core of ELM and pedestal changes are modeled as local effects.

The peak in $\omega_{\mathrm{E} \times \mathrm{B}}$ could be the cause of the pedestal and consequently of the ELMs. The large values of $\omega_{\mathrm{E} \times \mathrm{B}}$ found near the top of the pedestal increase the $\left|\omega_{\mathrm{E} \times \mathrm{B}}\right| / \gamma_{\text {lin }}$ suppression of transport, leading to an transport barrier. This barrier causes a pile-up of stored energy, increasing the energy density near the top of the pedestal. The energy that does leak out cascades down the pedestal either in a steady-state rate, or intermittently, with ELMs.

Our results linking $\left|\omega_{\mathrm{E} \times \mathrm{B}}\right| / \gamma_{\text {lin }}$ with increased transport and degradation of confinement suggests that tokamak reactors which rely on high density and high energy confinement in the ELMy H-mode may require a source of torque to maintain a high $\left|\omega_{\mathrm{E} \times \mathrm{B}}\right| / \gamma_{\text {lin }}$, at least near the top of the pedestal. It may prove more effective to drive poloidal than toroidal rotation since $E_{r}$ and $\omega_{\mathrm{E} \times \mathrm{B}}$ are generated by the sum $v_{P o l} B_{T o r}-v_{T o r} B_{P o l}$, although poloidal rotation is thought to be highly damped. It may be sufficient to apply a torque dipole near the top of the pedestal to generate large $\left|\omega_{E \times B}\right|$.

\section{Acknowledgment}

We wish to thank the members of the JET team for the excellent data and W. Dorland for help with the GS2 code. This work was supported in part by the US DoE Contract No. DE-AC02-76CH03073 


\begin{tabular}{||lll||}
\hline \hline Shot No. (year): & $43002(1997)$ & $49687(1999)$ \\
Type I $\rightarrow$ III transition: & Forced by gas puff & Spontaneous \\
Time traces: & Fig.1-a & Fig.1-b \\
\hline $\mathrm{R} / \mathrm{a}[\mathrm{m}]$ & $2.88 / 0.95$ & $2.94 / 0.90$ \\
$B_{\text {Tor }}[\mathrm{T}]$ & 2.8 & 2.0 \\
$I_{p}[\mathrm{MA}]$ & 2.6 & 1.9 \\
$P_{N B}[\mathrm{MW}]$ & $8\left(T^{0}\right)+3\left(D^{0}\right)$ & $5\left(D^{0}\right)$ \\
$n_{e}$ & increase & large decrease \\
$n_{e}(0) /<n_{e}>$ & $0.9 \rightarrow 1.1$ & $\approx 1.3$ \\
$\bar{n}_{e} / \bar{n}_{\text {Greenwald }}$ & $\rightarrow 0.85$ & $0.75 \rightarrow 0.35$ \\
$\beta_{n}$ & 1.53 & $1.9 \rightarrow 0.8$ \\
$f_{\text {tor }}$ & increase & large decrease \\
$\tau_{E}$ & 20 percent decrease & 50 percent decrease \\
$\chi_{\mathrm{i}}, \chi_{\text {eff }}$ & slight increase near pedestal & factor 2-3 increase \\
\hline \hline
\end{tabular}

Table 1: Summary of plasma parameters 


\section{References}

[1] L.D. Horton, R. Sartori, B. Balet, R.V. Budny, et al., Nucl. Fusion 39, 993 (1999).

[2] G. Saibene, L.D. Horton, R. Sartori, S. Clement, et al., Nucl. Fusion 39, 1133 (1999).

[3] JET Team prepared by L. D. Horton, IAEA-CN-77/EX2/1, presented at the Eighteenth International Conference on Plasma Physics and Controlled Fusion Research, Sorrento, Italy, 4-10 October 2000.

[4] A. Chankin and G. Saibene, Plasma Phys. and Contr. Fusion 41, 913 (1999).

[5] T.S. Hahm and K.H. Burrell, Phys. Plasmas 2, 1648 (1995).

[6] R.E. Waltz, G.D. Kerbel, and J. Milovich, Phys. Plasmas 1, 2229 (1994).

[7] M.A. Beer, R.V. Budny, C. Challis, G. Conway, et al., Contr. Fusion and Plasma Phys. 23J, 1669 (1999).

[8] E.J. Synakowski, S.H. Batha, M.A. Beer, et al., Phys. Rev. Lett. 78, 2972 (1997).

[9] H. Shirai, M. Kikuchi, T. Takizuka, T. Fujita, et al., Plasma Phys. Contr. Fusion 42, A81 (2000).

[10] D. R. Ernst, B. Coppi, S. Scott, M. Porkolab, and TFTR Group, Phys. Rev. Lett. 81, 2454 (1998).

[11] E.J. Synakowski, M.A. Beer, R.E. Bell, K.H. Burrell, et al., Nucl. Fusion 39, 1733 (1999).

[12] R. LaHaye, T.H. Osborne, C.L. Rettig, C.M. Greenfield, et al., Nucl. Fusion 35, 988 (1995).

[13] R.V. Budny, J.P. Christiansen, J.G. Cordey, D.R. Ernst, et al., Phys. of Plasmas 7, 5038 (2000).

[14] JET Team, presented by R.V. Budny, IAEA-CN-77/EXP5/19, presented at the Eighteenth International Conference on Plasma Physics and Controlled Fusion Research, Sorrento, Italy, 4-10 October 2000.

[15] C. Gowers, B. Brown, H. Fajemirokun, P. Nielsen, et al., Rev. Sci. Instruments 66, 471 (1995).

[16] M. von Hellermann and H. Summers, Atomic and Plasma Material Interaction Processes in Controlled Thermonuclear Fusion, edited by Janev, Elsevier, 1993, p. 135.

[17] N. Hawkes and N. Peacock, Rev. Sci. Instruments 63, 5164 (1992). 
[18] R.V. Budny, M.A. Bell, H. Biglari, A. Janos, et al., Nucl. Fusion 35, 1497 (1995).

[19] W. Houlberg, K. Shang, S. Hirshman, and M. Zarnstorff, Phys. Plasmas 4, 3230 (1997).

[20] D. Ernst, M. Bell, C. Bush, Z. Chang, et al., Phys. of Plasmas 5, 665 (1998).

[21] W. Dorland, B.N. Rogers, F. Jenko, et al., IAEA-CN-77/TH2/5, presented at the Eighteenth International Conference on Plasma Physics and Controlled Fusion Research, Sorrento, Italy, 4-10 October 2000, M. Kotschenreuther, G. Rewoldt, and W. Tang, Comp. Phys. Comm. 88, 128 (1995).

[22] D.R. Ernst, R.E. Bell, M.G. Bell, R.V. Budny, et al., Phys. of Plasmas 7, 615 (2000).

[23] A.M. Dimits, G. Batemann, M.A. Beer, B.I. Cohen, et al., Phys. Plasmas 7, 969 (2000).

[24] M. Kotschenreuther, W. Dorland, M. Beer, and G. Hammett, Phys. Plasmas 2, 2381 (1995).

[25] Z. Lin, T. Hahm, W. Lee, W. Tang, and P. Diamond, Phys. Rev. Lett. 83, 3645 (1999). 


\section{Figure Captions}

Fig. 1 - Waveforms a) 43002 with intense gas puff and b) 49687 with a spontaneous Type I $\rightarrow$ III ELM transition; bottom: microturbulence suppression ratio as several radii near the top of the pedestal. Vertical dashed lines indicate analysis times.

Fig. 2 - Thermal energy densities mapped to the toroidal flux label.

Fig. 3 - Measured $T_{i}$ mapped to the toroidal flux label.

Fig. 4 - Measured $R / L_{T i}$ mapped to the toroidal flux label.

Fig. 5 - Measured toroidal rotation frequency mapped to the toroidal flux label.

Fig. 6 - Comparison of measured and TRANSP-calculated stored energies.

Fig. 7 - NBI torque density profiles.

Fig. 8 - Thermal ion energy transport coefficient vs major radius and toroidal flux label $\mathrm{x}$. Vertical dashed lines indicate approximate location of top of pedestal.

Fig. 9 - Shearing rate.

Fig. 10 - Spectra of $\gamma_{\text {lin }}, \omega_{\text {lin }}$, and the mixing length estimate of $\chi_{\mathrm{i}}$ at $\mathrm{x}=0.775(\mathrm{R}=3.74 \mathrm{~m})$.

Fig. 11 - Spectra of maximum growth rate $\gamma_{\text {lin }}$, mode frequency $\omega_{\text {lin }}$, and the mixing length estimate of $\chi_{i}$ at $x=0.875(R=3.77 \mathrm{~m})$.

Fig. 12 - Comparison of $R / L_{T i}$ and $R / L_{\text {crit }}$ estimated by the IFS-PPPL model vs toroidal flux label.

Fig. 13 - Profiles of $\gamma_{\text {lin }}, \omega_{\text {lin }}$, and $\omega_{\mathrm{E} \times \mathrm{B}}$ at one time during the low confinement phases.

Fig. 14 - Profiles of $\gamma_{\text {lin }}$ at different times. 


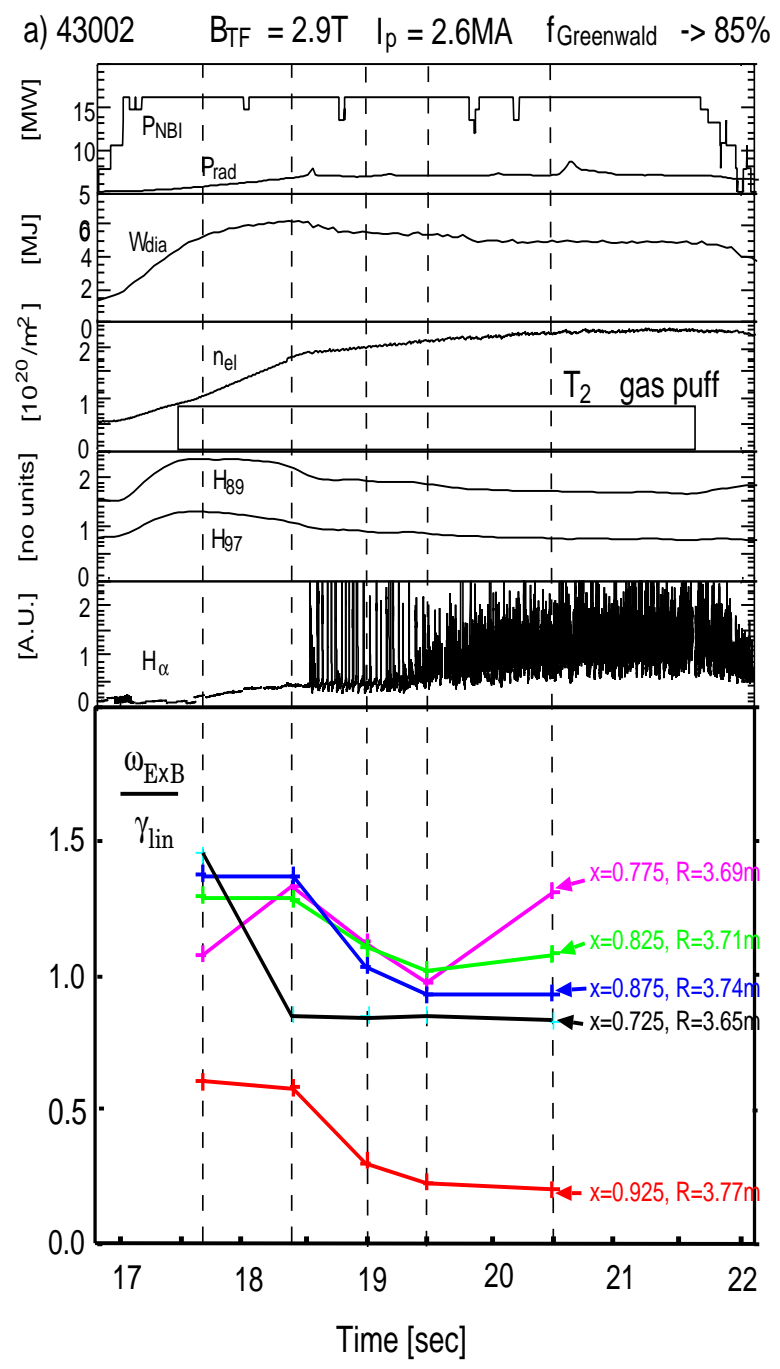

b) $49687 \mathrm{BTF}_{\mathrm{TF}}=2.0 \mathrm{~T} \mathrm{I}_{p}=1.9 \mathrm{MA} \mathrm{f}_{\text {Greenwald }} 75 \%->35 \%$

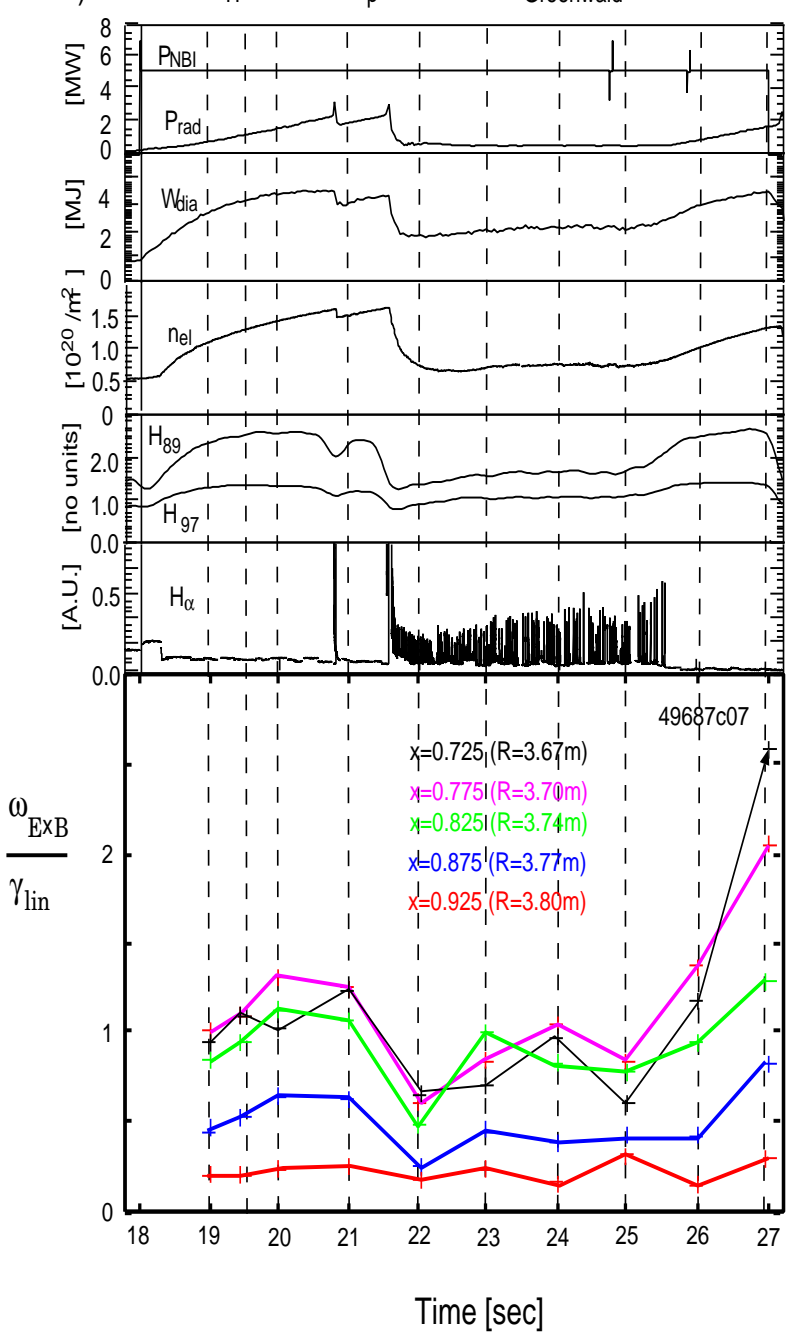

Figure 1:
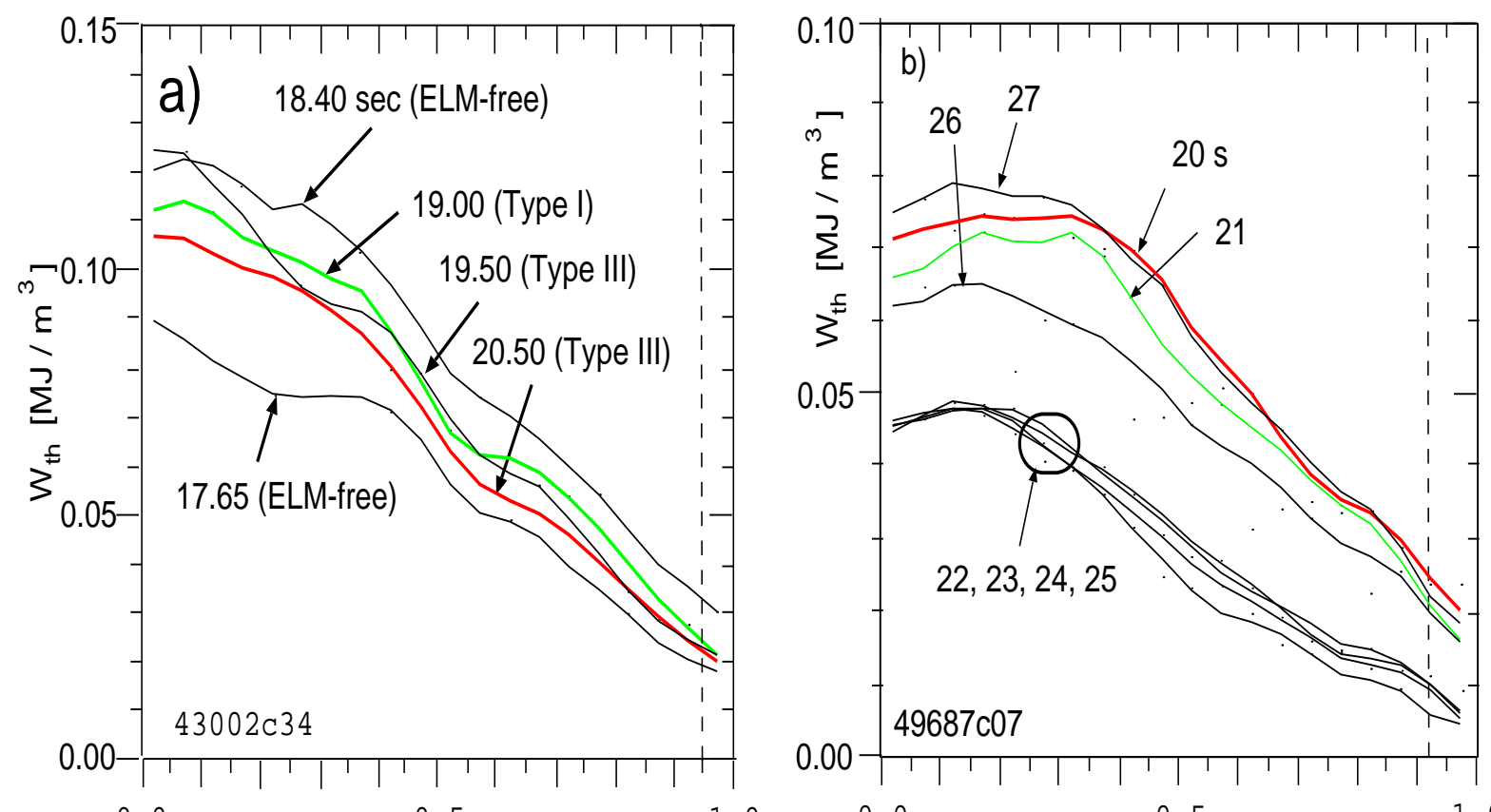
0.0
0.5
1.0

0.0

0.5

1.0

Toroidal flux label $\mathrm{x}$

Toroidal flux label $x$

Figure 2: 


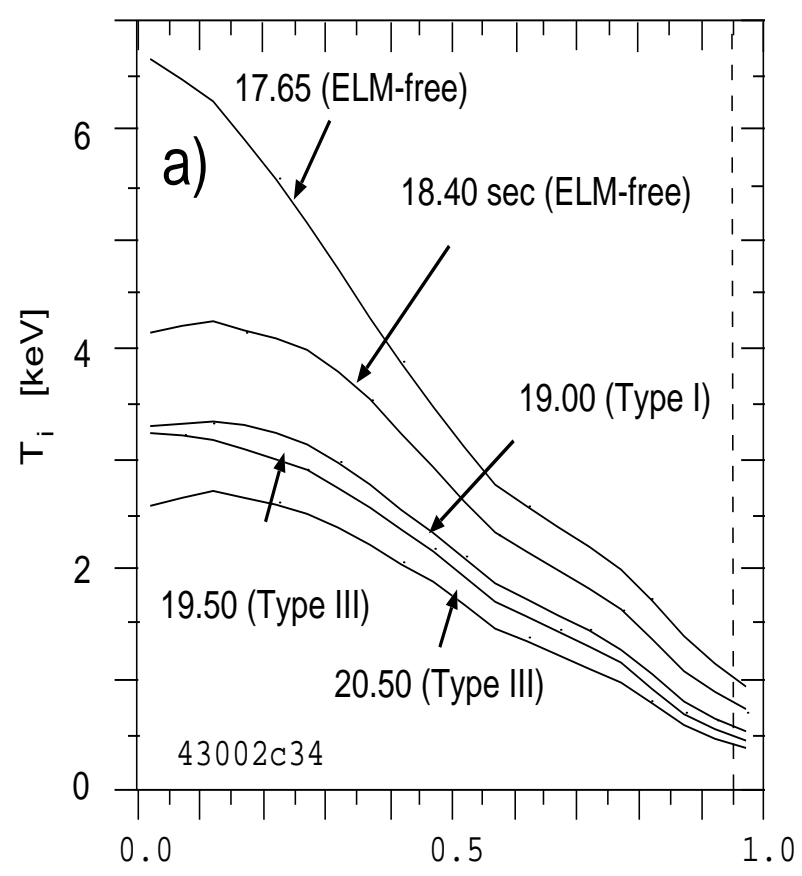

Toroidal flux label $\mathrm{x}$

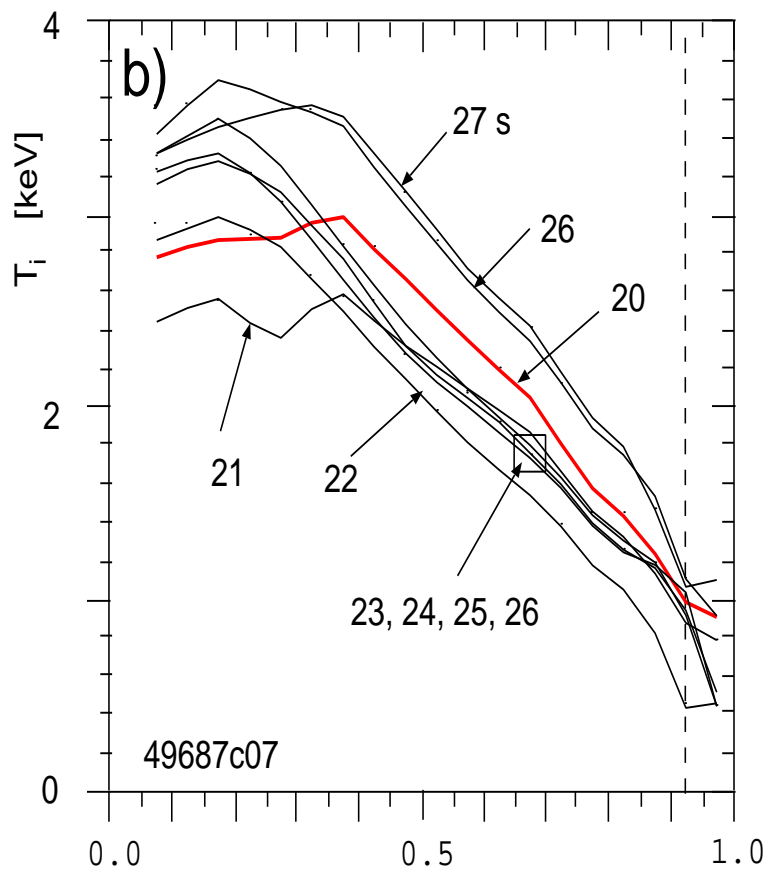

Toroidal flux label $x$

Figure 3:

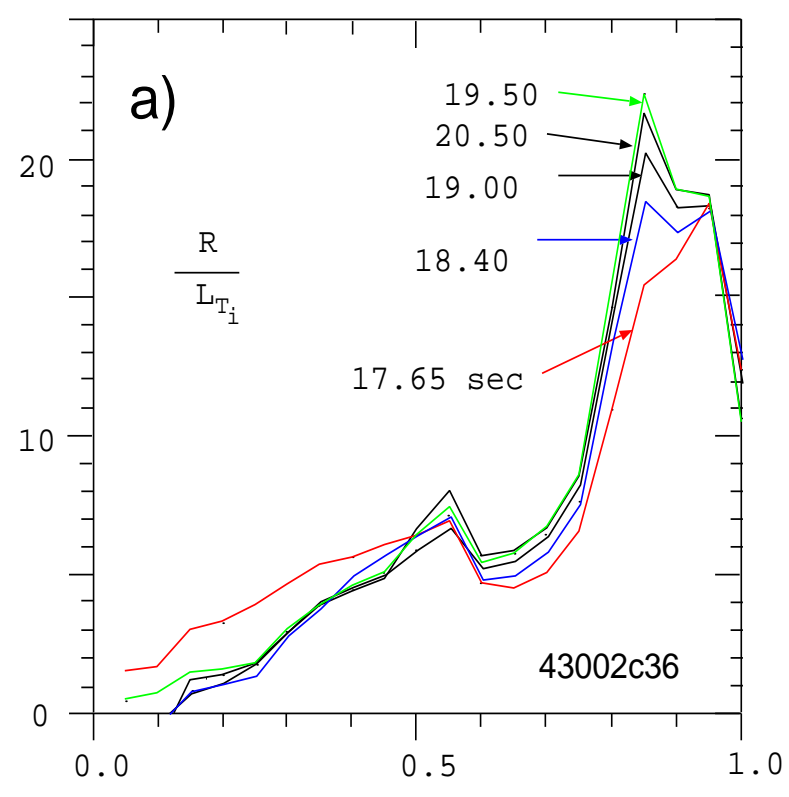

Toroidal flux label $x$

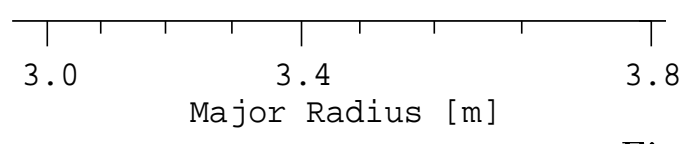

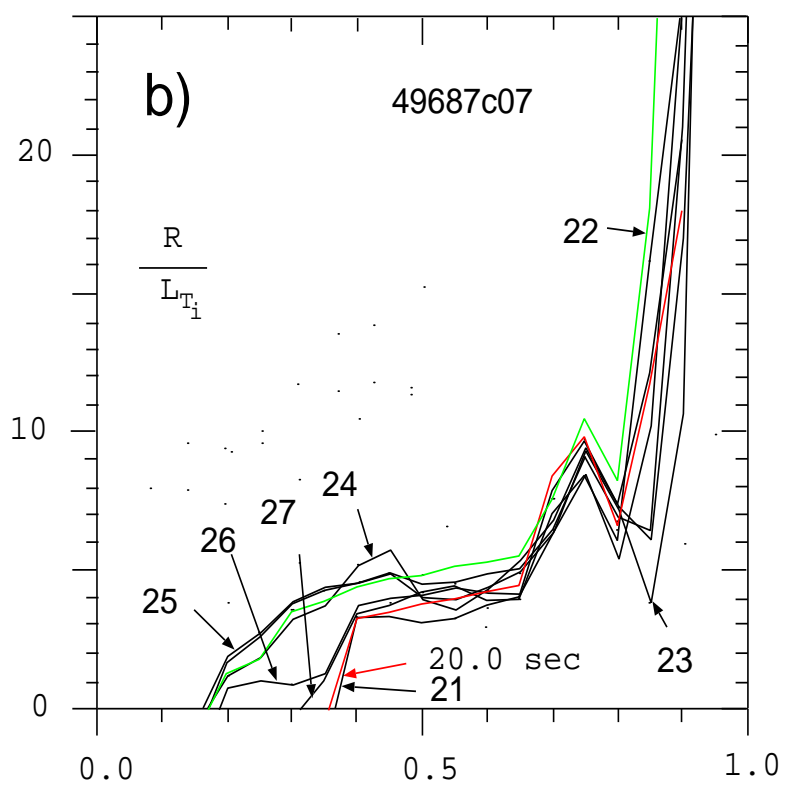

Toroidal flux label $\mathrm{x}$

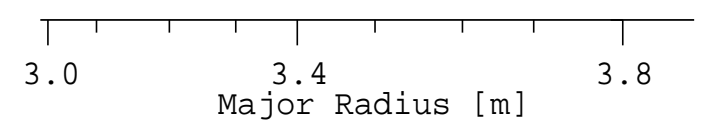

Figure 4: 


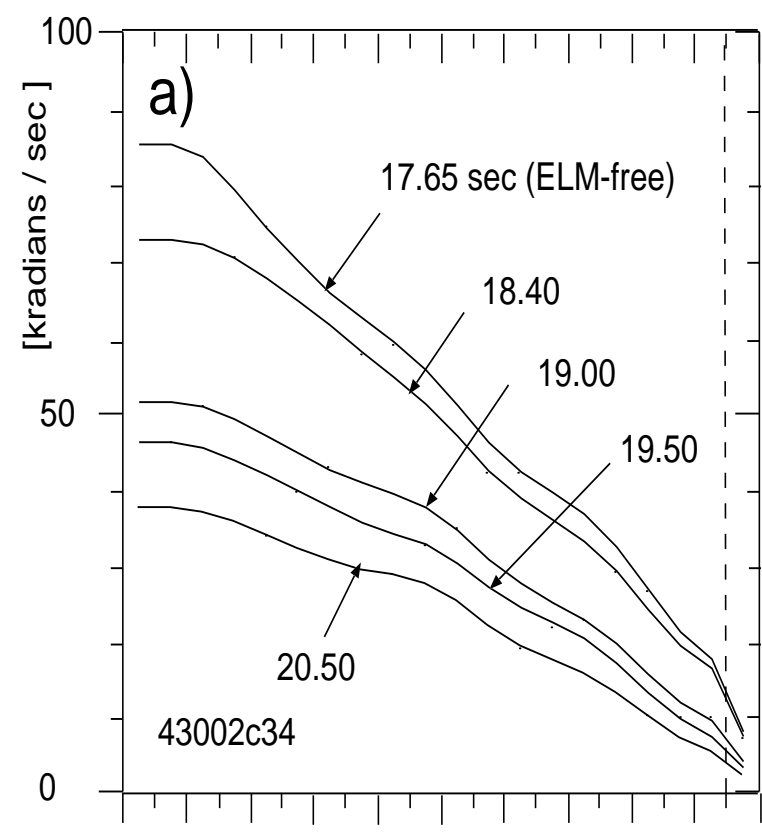

0.0
0.5

Toroidal flux label $\mathrm{x}$

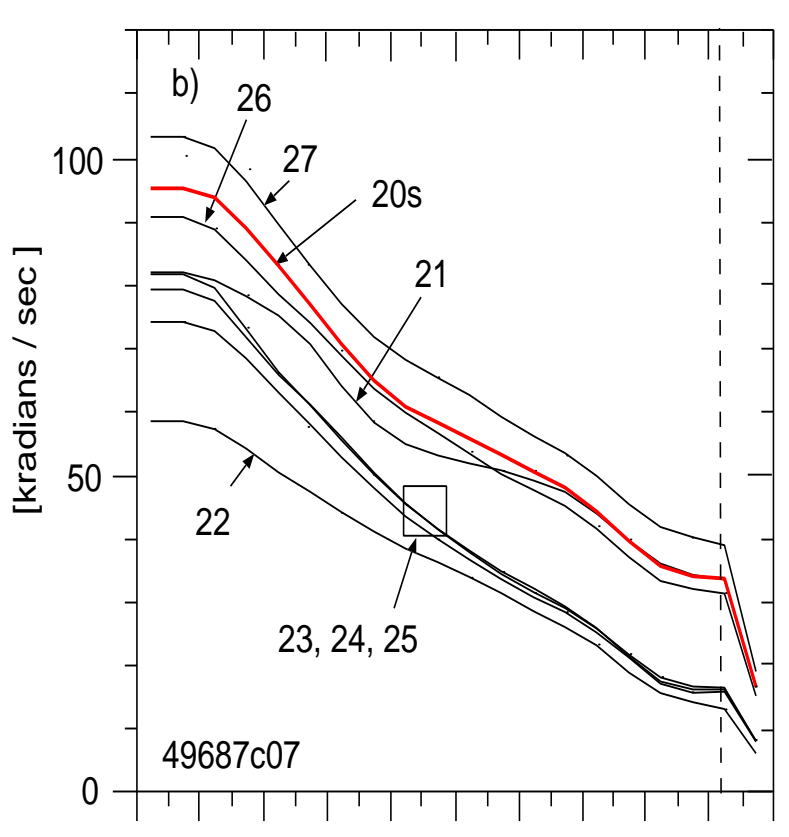

1.0

0.5

1.0

Toroidal flux label $\mathrm{x}$

Figure 5:
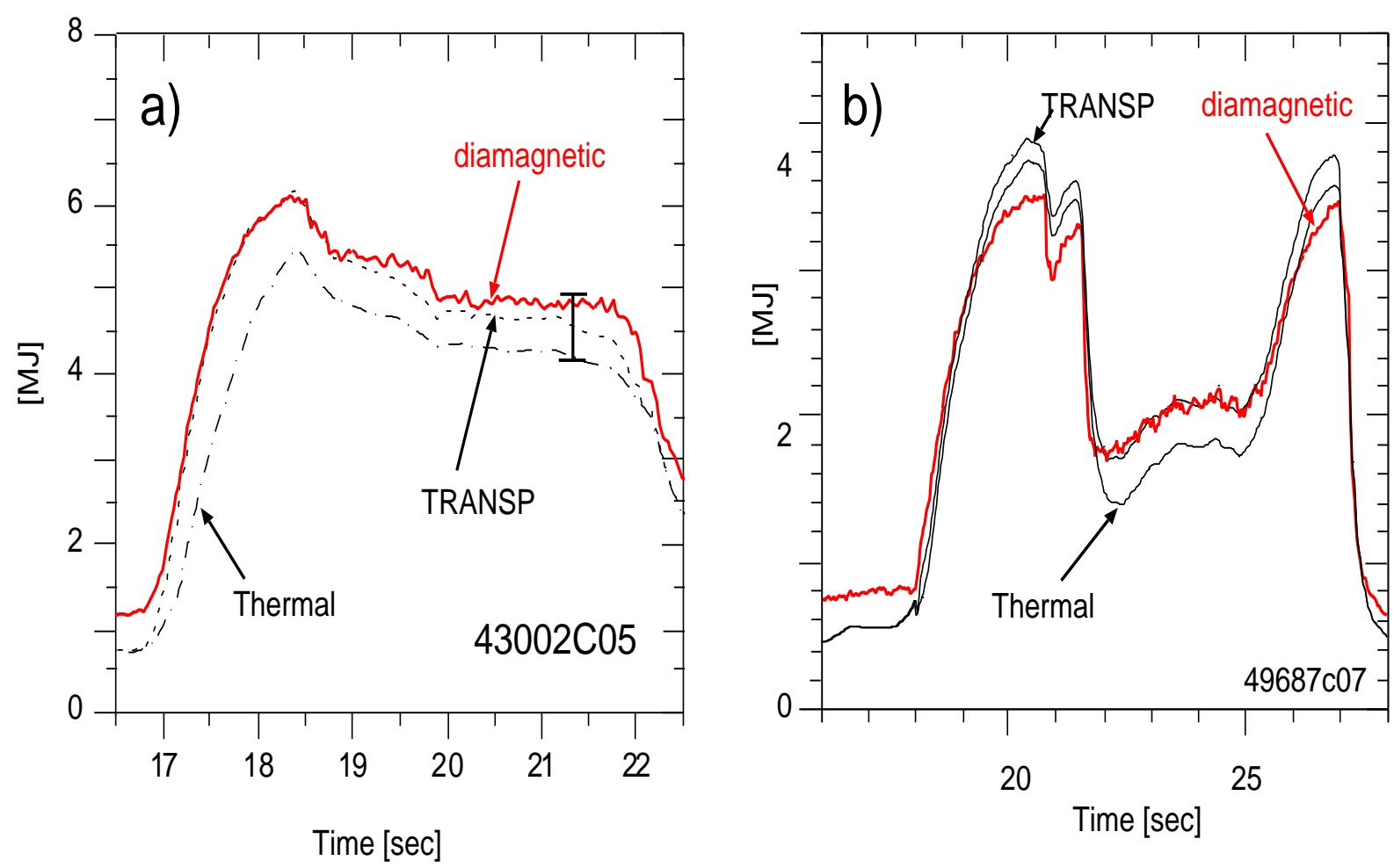

Figure 6: 


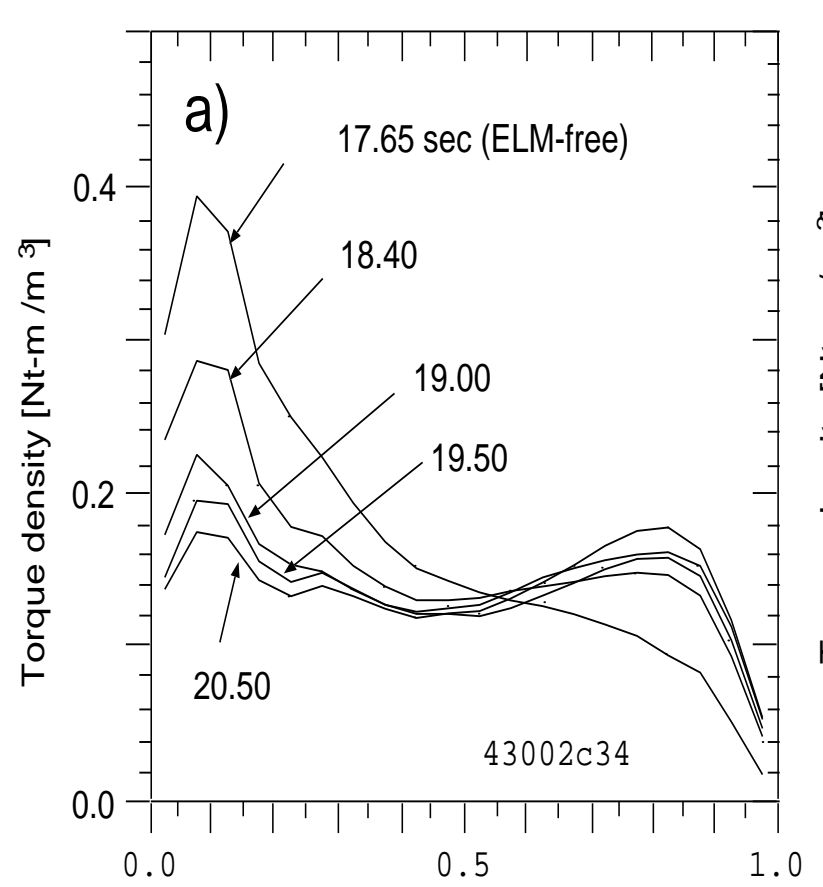

Toroidal flux label $\mathrm{x}$

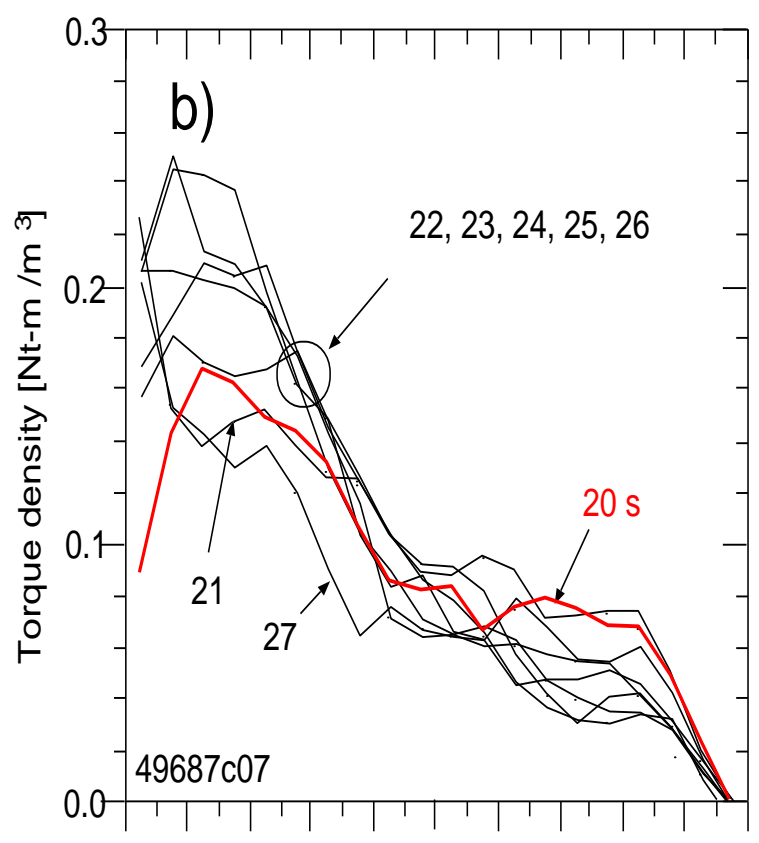

0.0
0.5

Toroidal flux label $x$

Figure 7:
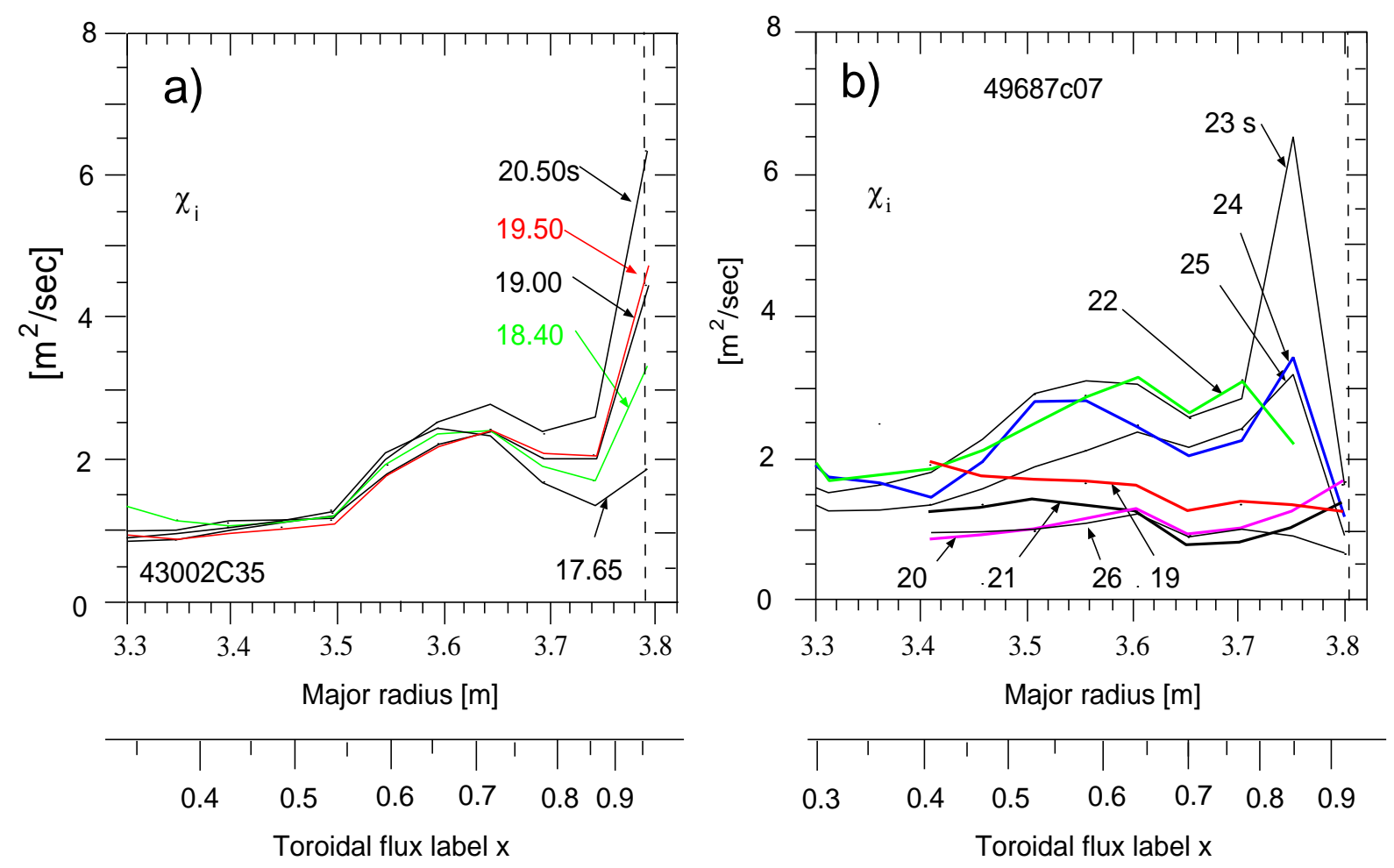

Figure 8: 

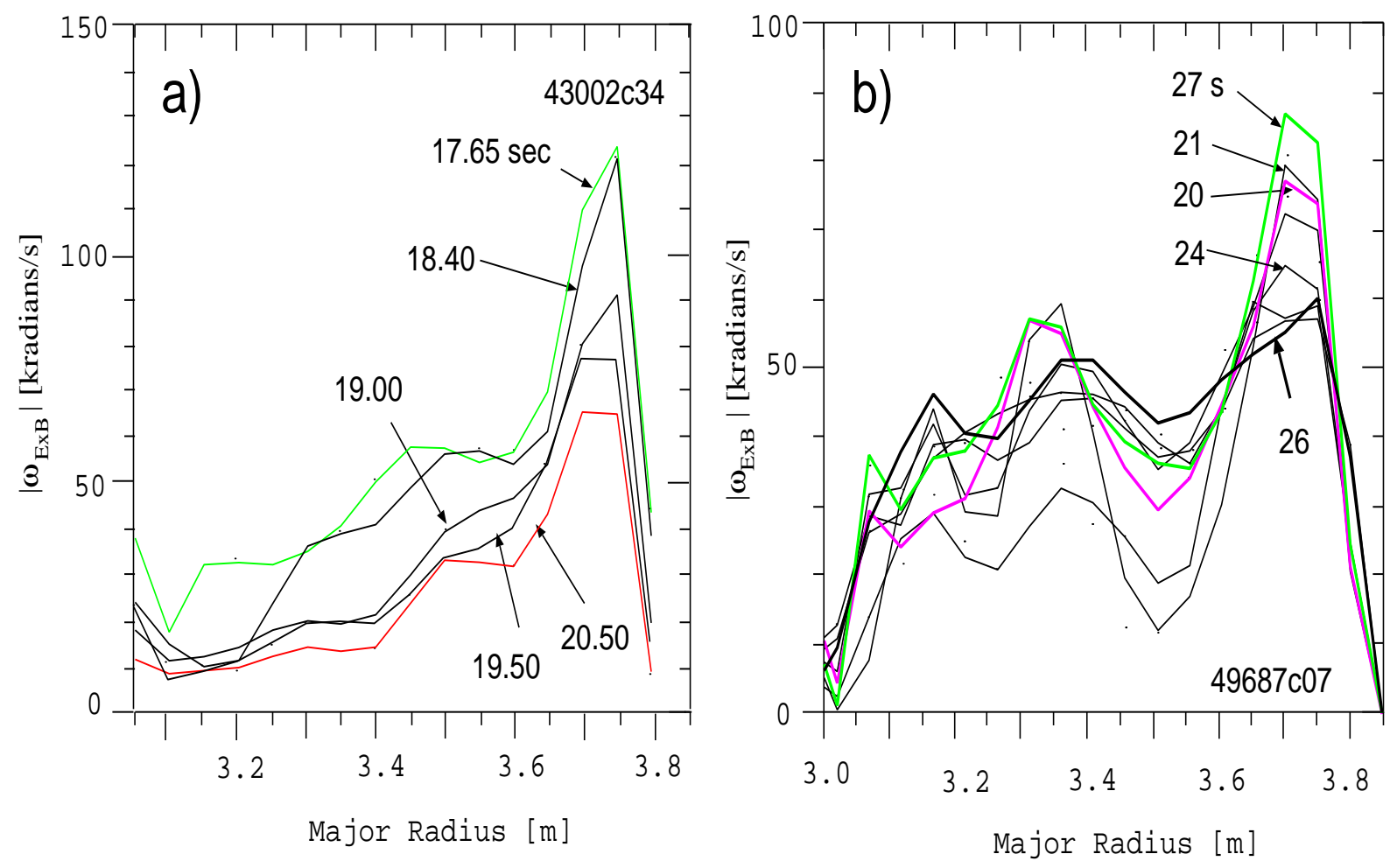

Figure 9:
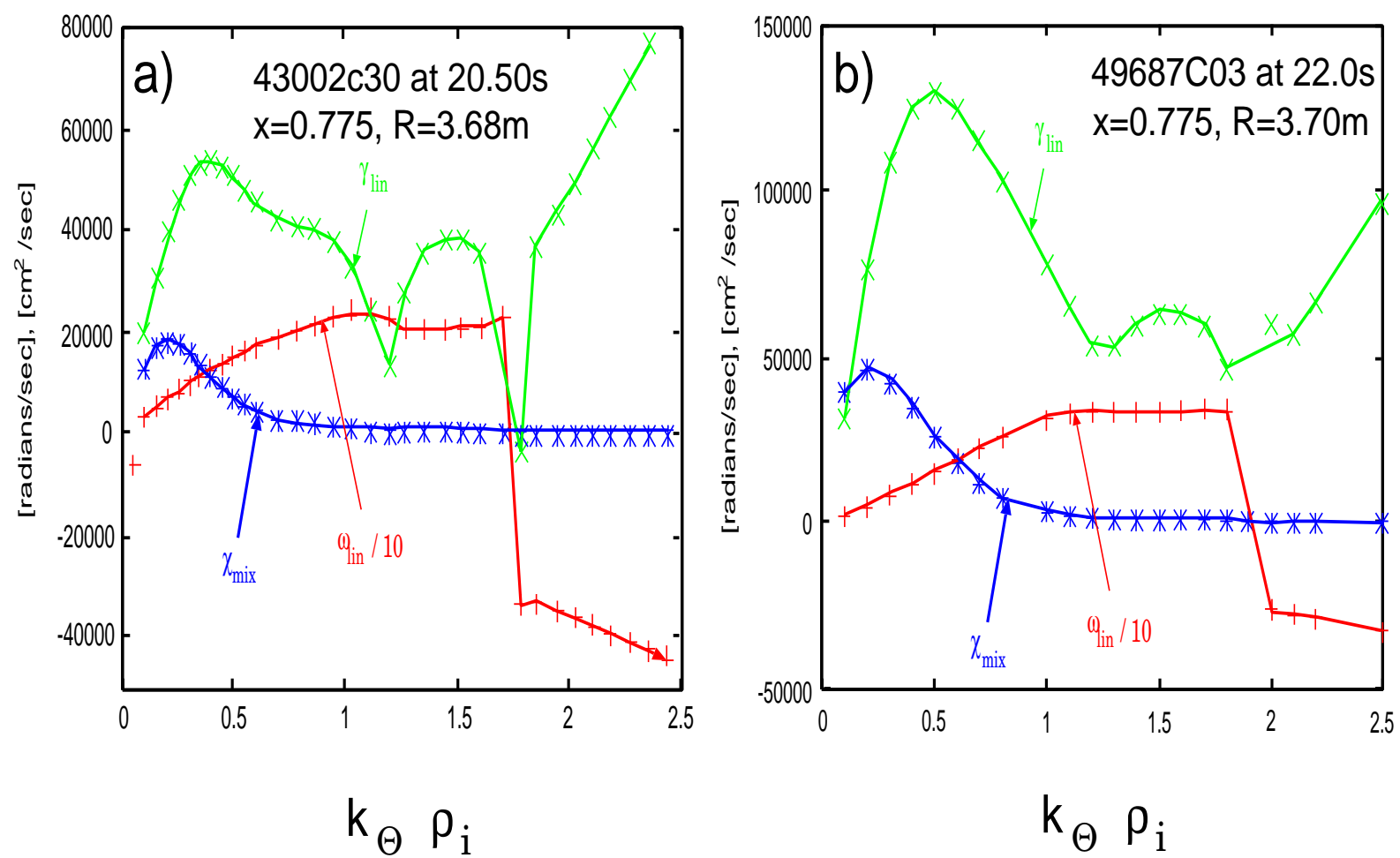

Figure 10: 

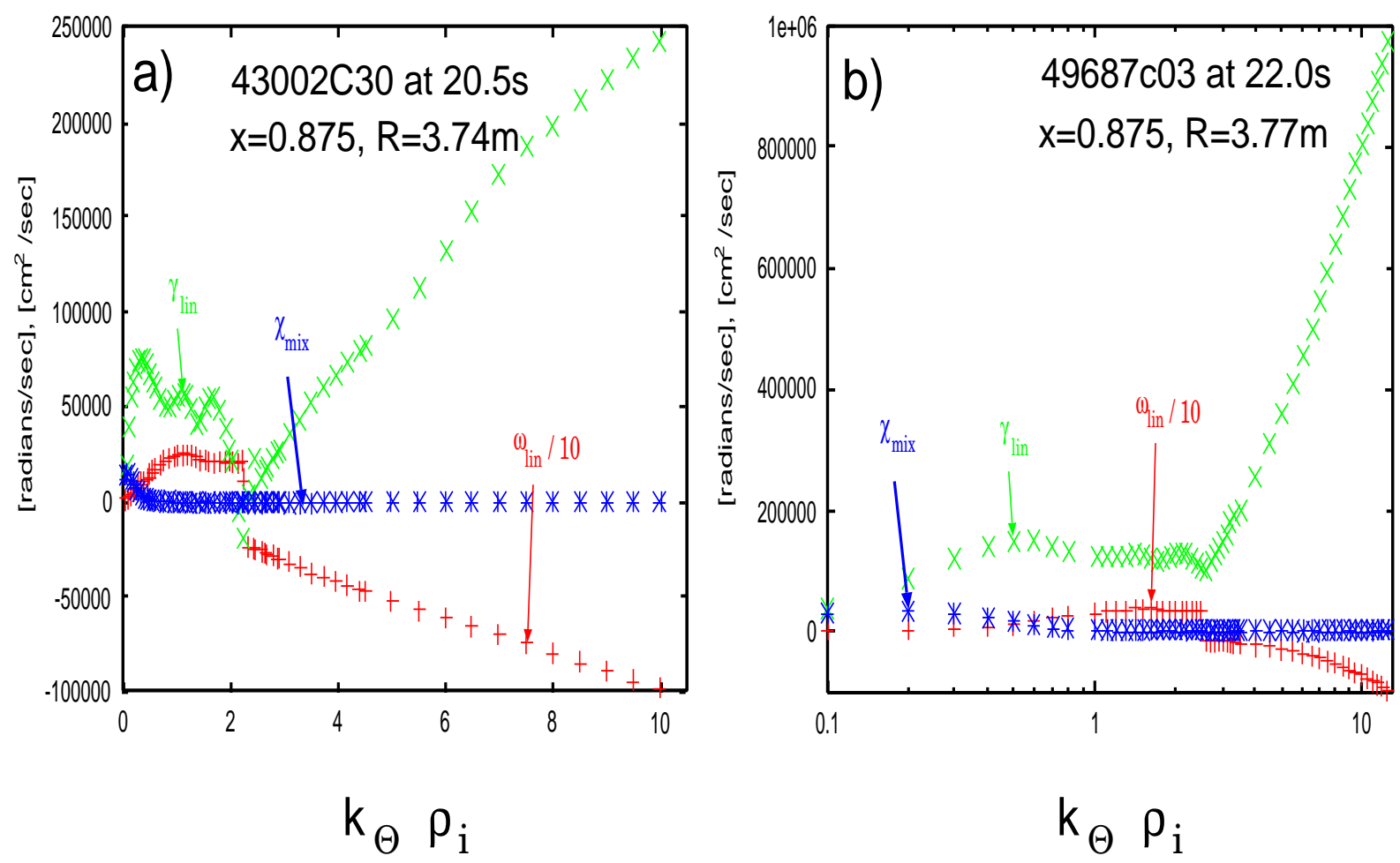

Figure 11:

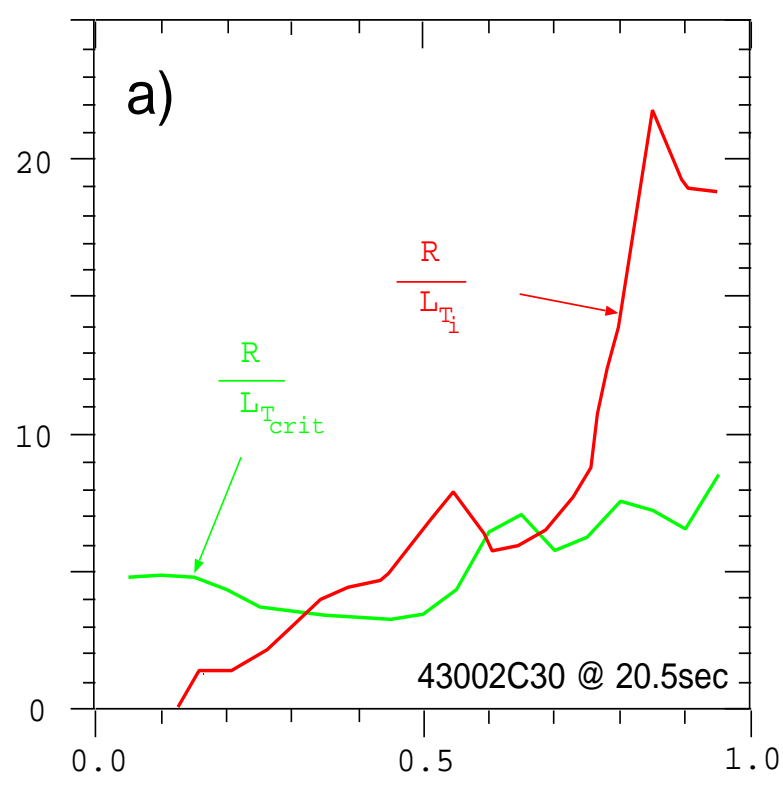

Toroidal flux label $\mathrm{x}$

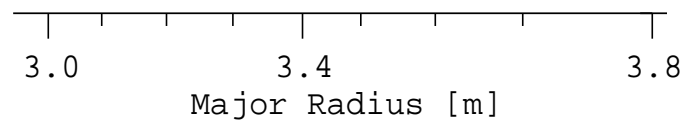

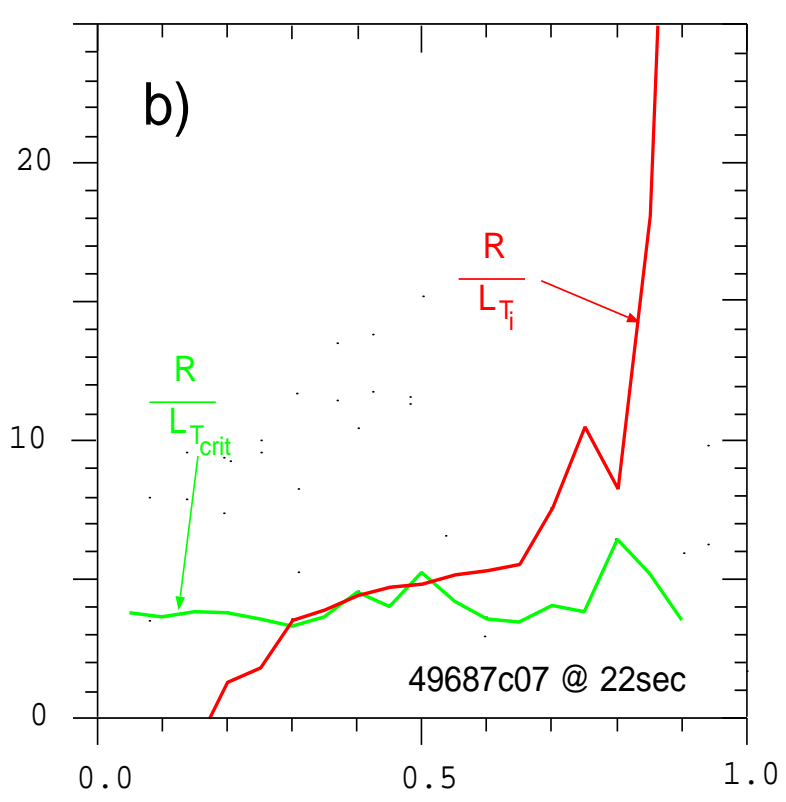

Toroidal flux label $\mathrm{x}$

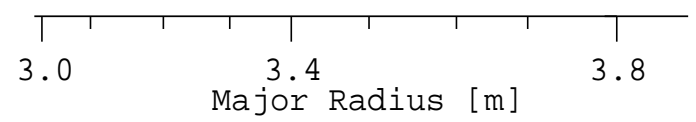

Figure 12: 


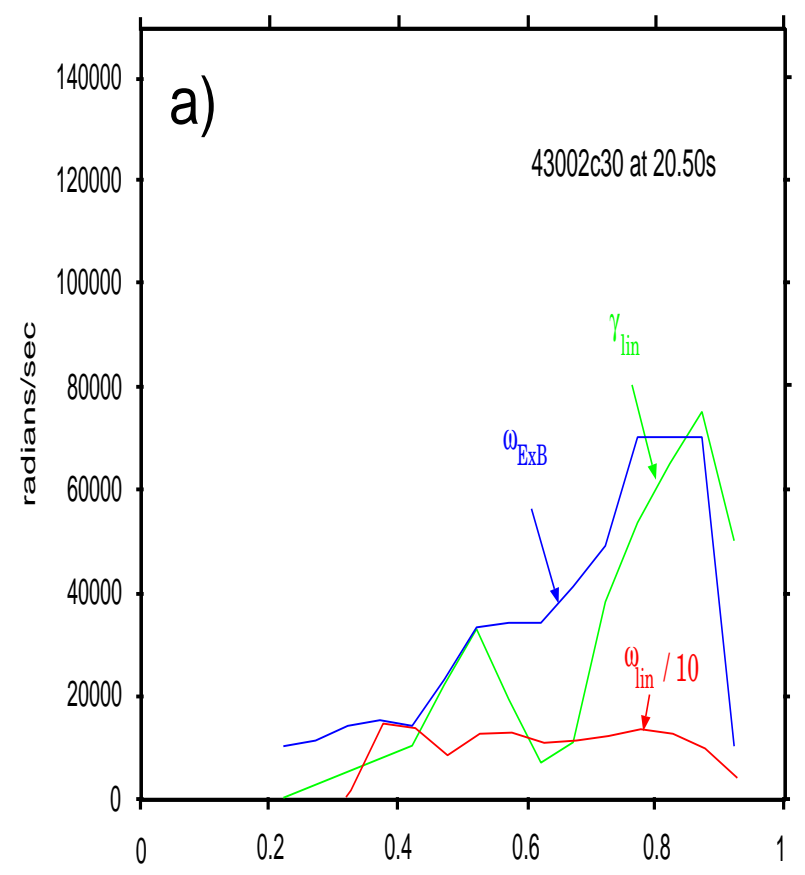

Toroidal flux label $\mathrm{x}$

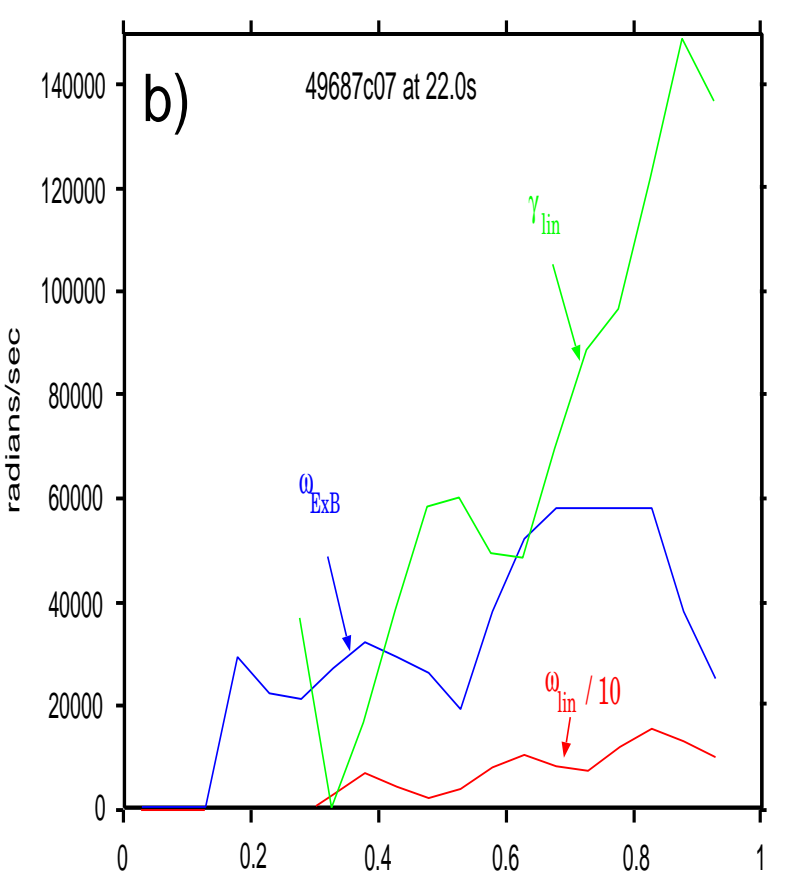

Toroidal flux label $\mathrm{x}$

Figure 13:

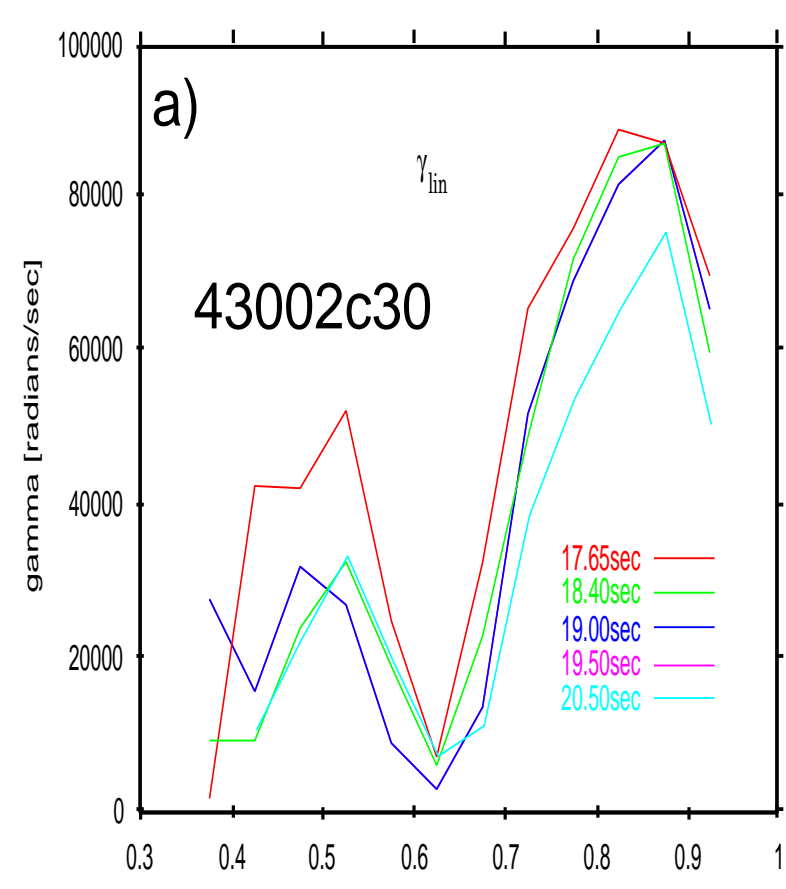

Toroidal flux label $\mathrm{x}$

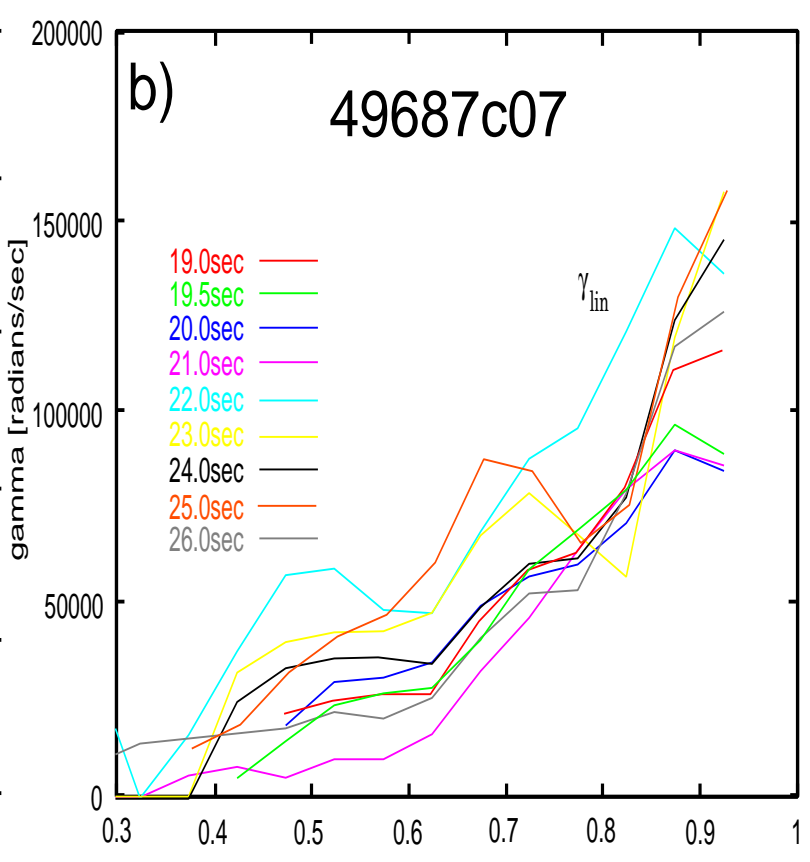

Toroidal flux label $\mathrm{x}$

Figure 14: 


\section{External Distribution}

Plasma Research Laboratory, Australian National University, Australia

Professor I.R. J ones, Flinders University, Australia

Professor J oão Canalle, Instituto de Fisica DEQ/IF - UERJ , Brazil

Mr. Gerson O. Ludwig, Instituto Nacional de Pesquisas, Brazil

Dr. P.H. Sakanaka, Instituto Fisica, Brazil

The Librarian, Culham Laboratory, England

Library, R61, Rutherford Appleton Laboratory, England

Mrs. S.A. Hutchinson, JET Library, England

Professor M.N. Bussac, Ecole Polytechnique, France

Librarian, Max-Planck-Institut für Plasmaphysik, Germany

J olan Moldvai, Reports Library, MTA KFKI-ATKI, Hungary

Dr. P. Kaw, Institute for Plasma Research, India

Ms. P.J . Pathak, Librarian, Insitute for Plasma Research, India

Ms. Clelia De Palo, Associazione EURATOM-ENEA, I taly

Dr. G. Grosso, Instituto di Fisica del Plasma, Italy

Librarian, Naka Fusion Research Establishment, J AERI, J apan

Library, Plasma Physics Laboratory, Kyoto University, J apan

Research Information Center, National Institute for Fusion Science, J apan

Dr. O. Mitarai, Kyushu Tokai University, J apan

Library, Academia Sinica, Institute of Plasma Physics, People's Republic of China

Shih-Tung Tsai, Institute of Physics, Chinese Academy of Sciences, People's Republic of China

Dr. S. Mirnov, Triniti, Troitsk, Russian Federation, Russia

Dr. V.S. Strelkov, Kurchatov Institute, Russian Federation, Russia

Professor Peter Lukac, Katedra Fyziky Plazmy MFF UK, Mlynska dolina F-2, Komenskeho Univerzita, SK-842 15 Bratislava, Slovakia

Dr. G.S. Lee, Korea Basic Science Institute, South Korea

Mr. Dennis Bruggink, Fusion Library, University of Wisconsin, USA

Institute for Plasma Research, University of Maryland, USA

Librarian, Fusion Energy Division, Oak Ridge National Laboratory, USA

Librarian, Institute of Fusion Studies, University of Texas, USA

Librarian, Magnetic Fusion Program, Lawrence Livermore National Laboratory, USA

Library, General Atomics, USA

Plasma Physics Group, Fusion Energy Research Program, University of California at San Diego, USA

Plasma Physics Library, Columbia University, USA

Alkesh Punjabi, Center for Fusion Research and Training, Hampton University, USA

Dr. W.M. Stacey, Fusion Research Center, Georgia Institute of Technology, USA

Dr. J ohn Willis, U.S. Department of Energy, Office of Fusion Energy Sciences, USA

Mr. Paul H. Wright, Indianapolis, Indiana, USA 
The Princeton Plasma Physics Laboratory is operated by Princeton University under contract with the U.S. Department of Energy.

\author{
Information Services \\ Princeton Plasma Physics Laboratory \\ P.O. Box 451 \\ Princeton, NJ 08543
}

Phone: 609-243-2750

Fax: 609-243-2751

e-mail: pppl_info@pppl.gov

Internet Address: http://www.pppl.gov 